\title{
BASELINE MEASUREMENT OF THE IMPLEMENTATION PROCESS OF THE PROPOSED MODEL FOR CLINICAL NURSING EDUCATION AND TRAINING IN SOUTH AFRICAN UNIVERSITIES
}

Professor Magda Mulder: University of the Free State

Professor Leana R Uys: University of KwaZulu-Natal

\begin{abstract}
Clinical teaching and learning of nursing students are part of work-integrated learning. In 2010 the Nursing Education Stakeholders identified clinical teaching as a weak point in nursing education in South Africa and developed a Clinical nursing education and training model to address the deficiencies.
\end{abstract}

Although this model has not been formally accepted by the South African Nursing Council, it was accepted by the Nursing Summit delegates and by FUNDISA in 2011. The University Nursing Schools are therefore in the process of implementing the model and FUNDISA has targeted this programme as one of three it will be monitoring and evaluating over the next five years.

Methodology: A questionnaire survey was undertaken and the specific objectives were to:

- $\quad$ assess to what extent the proposed model is currently implemented in pre-registration nursing programmes at Universities

- $\quad$ identify problems that were experienced during implementation of the proposed model

Main Results: Only four of the 11 Universities that participated have provided targeted formalized training for preceptors. The ratios between clinical preceptors and students are slightly less favourable especially during the first and second years.

There is also no structured way in which nurse academics are required to keep themselves clinically competent. Three of the five problems that Schools are experiencing with implementation of the model are related to the clinical practice environments.

Recommendations: It was recommended that Nursing Schools only place students in Positive Practice Environments and that Nursing Schools present workshops on the clinical nursing education and training model in order for their Staff to become familiar with the components and nomenclature of the model. Researchers must also focus on targeted aspects of the model, such as the impact of limited preceptors during the first 2 years of training or the impact of pre- and post-clinical conferences on student learning and experience.

Keywords: Clinical education and training; clinical training; Nursing Education Stakeholders 


\section{Introduction}

It is an international phenomenon that students are present in clinical settings as learners and not as part of the workforce and are therefore regarded as supernumerary. Students are not allowed to be employed by entering into a contract to render nursing care (NMC, 2004 b; NMC 2004 c; Harwood et al., 2009). Various funding programs to address the shortage of registered nurses have been implemented in the United States as recruitment and retention strategies. Education grants are offered to expand enrolments in nursing baccalaureate programs. These support education programs to double nurse retention rates and increase nurse satisfaction. A total of $85 \%$ of the registered nurse student educational loans are repaid over a period of four years by the Nurse Faculty Loan Programme which establishes funds within schools of nursing to increase the number of qualified educators. In return, once their studies are complete, registered nurses are expected to teach at a school of nursing to address the shortage of nurse educators, a result of an aging population (American Nurses Association, April 2011).

Clinical teaching and learning are part of work-integrated learning (WIL) and refer to workplace learning. WIL is a topic which is receiving much attention by the Council on Higher Education (CHE) of South Africa at the moment. According to the CHE, WIL is based on "a common understanding of the importance of enabling students to integrate theoretical knowledge gained through formal study, with practice-based knowledge gained through immersion in a work or professional context" (CHE, 2011:4). They see a direct relationship between the way a subject is taught in class and the way it is taught and applied in the workplace (see Figure 1). The case-based approach to teaching and learning is one strategy which lends itself to creating a direct relationship between what students learn in theory and what they learn in practice.

According to Mekwa (2001), in South Africa the recognition, by the Higher Education Act No. 101 of 1997, of nursing education as part of mainstream higher education is a significant achievement which, if successfully completed, grants the nursing profession equal status with other professions. However, student status in the workplace remains a concern and affects the success of WIL. To this end, the Nursing Compact which is described in Chapter 3, an outcome of the National Nursing Summit held in April 2011, urged the South African Government to prioritise the creation of a conducive learning environment for student nurses through standardization of financial support for students.

In the university sector, the initiation of the Clinical Training Grant from the Department of Higher Education and Training has made a significant difference to the ability of nursing schools to address deficiencies in clinical teaching. This is an earmarked grant made available to all universities on a prorata basis to assist them with the cost of providing clinical teaching and learning opportunities to undergraduate students in the health professions. Depending on the size of the school, this has meant an annual grant of millions of Rand for nursing schools, enabling them to strengthen clinical teaching in many ways such as design and build clinical simulation laboratories, buy simulation equipment, build student residences at distant clinical sites, appoint more clinical preceptors. 


\begin{tabular}{|c|c|c|c|}
\hline \multirow{2}{*}{$\begin{array}{c}1 \\
\text { The academic } \\
\text { field }\end{array}$} & \multicolumn{2}{|c|}{$\begin{array}{c}2 \\
\text { The educational field }\end{array}$} & \multirow{2}{*}{$\begin{array}{c}3 \\
\text { Professional } \\
\text { Practice }\end{array}$} \\
\hline & $\begin{array}{l}\text { Discipline } \\
\text { oriented }\end{array}$ & $\begin{array}{l}\text { Discipline oriented } \\
\text { education }\end{array}$ & \\
\hline $\begin{array}{l}\text { Academic staff, } \\
\text { usually acting as } \\
\text { researchers } \\
\text { develop new } \\
\text { knowledge and } \\
\text { thinking in their } \\
\text { field of } \\
\text { specialisation }\end{array}$ & $\begin{array}{l}\text { Academic staff } \\
\text { select academic } \\
\text { students to } \\
\text { study, devise } \\
\text { methods of } \\
\text { teaching and } \\
\text { assessment that } \\
\text { are appropriate } \\
\text { to students' } \\
\text { conceptual } \\
\text { development }\end{array}$ & $\begin{array}{l}\text { Academic staff } \\
\text { select professional } \\
\text { concepts and skills } \\
\text { for their students } \\
\text { to study, devise } \\
\text { methods of } \\
\text { teaching and } \\
\text { assessment that } \\
\text { are appropriate to } \\
\text { student's } \\
\text { professional } \\
\text { development }\end{array}$ & $\begin{array}{l}\text { Professionals } \\
\text { transfer/transfo } \\
\mathrm{rm} \text { the } \\
\text { knowledge } \\
\text { learning at } \\
\text { university in } \\
\text { their field of } \\
\text { practice. }\end{array}$ \\
\hline
\end{tabular}

Figure 5.1: A professional knowledge system in a Work Integrated Learning approach (CHE, 2011: 9)

\section{Clarification of concepts}

In 2010, the Nursing Education Stakeholders identified clinical teaching as a weak point in nursing education in South Africa and developed a clinical nursing education and training model to address the deficiencies. This model has been described in Chapter 4. The current chapter deals with the implementation of this model by the university sector.

\section{Problem statement}

Although the model for clinical nursing education and training has not been formally accepted by the SA Nursing Council, it was accepted by the Nursing Summit delegates and by FUNDISA in 2011. The university nursing schools are therefore in the process of implementing the model and, in line with its advocacy role and its commitment to promoting policy research, FUNDISA has targeted this programme as one of three it will be monitoring and evaluating over the next five years. Too often in the past the implementation of policies was not tracked, so that the level of implementation remained unclear. Furthermore, the impact of policies on education practice was inadequately documented, leading to policy decisions that had little evidence to support them. 
As University Schools of Nursing embark on the implementation of the proposed model for clinical nursing education and training (see Chapter 4), it is important to monitor and evaluate the implementation process in order to acquire a baseline measurement to which future performance can be compared. Without such a measurement, it will not be possible to ascribe any changes to the

implementation of the new model or to identify both positive and negative aspects about the implementation process.

\section{Aim and objectives of the survey}

The aim of the study was, therefore, to establish a baseline measurement of the state of clinical teaching in terms of the proposed clinical nursing education and training model.

Specific objectives were to:

- $\quad$ assess to what extent the proposed model for clinical nursing education and training is currently implemented in pre-registration nursing programmes at Universities;

- $\quad$ identify problems that were experienced during implementation of the proposed model for clinical nursing education and training.

\section{Methods}

This was a questionnaire-based survey including all University nursing schools with a pre-registration Bachelor in Nursing or Bachelor of Technology degree in Nursing. A descriptive study was done using both quantitative and qualitative data.

\section{Sample}

The questionnaire was distributed to the 22 South African universities, who have nursing schools. Only 18 of these universities offer pre-registration nursing degrees, after two reminders, the following 11 nursing schools responded, amounting to a $61 \%$ response rate.

1. Adelaide Tambo School of Nursing at the Tshwane University of Technology (TUT) (Gauteng)

2. Durban University of Technology (DUT)

3. University of the Free State (UFS)

(KwaZulu-Natal)

4. University of Limpopo (Turfloop campus (UL)

(Free State)

5. Nelson Mandela Metropolitan University (NMMU)

(Limpopo)

6. North West University (Potchefstroom) (NWU-P)

(Eastern Cape)

7. North West University (Mafikeng) (NWU-M)

(North-West Province)

8. Pretoria University (UP) (North-West Province)

9. Walter Sisulu University (WSU)

(Gauteng)

10. University of the Western Cape (UWC)

(Eastern Cape)

11. University of the Witwatersrand (WITS)

(Western Cape)

(Gauteng) 


\section{Data collection}

A questionnaire was developed consisting of the following components:

- Student data (4 items)

- Dedicated clinical teaching staff and their work (13 items)

- Curriculum principles (5 items)

- Academic staff and their work (7 items)

- Clinical placement (8 items)

- Implementation of the model (4 items).

These components included open-ended items (e.g. number of students in each year of study), a checklist (e.g. academics have to spend a certain portion of their sabbatical leave working in the clinical field; Yes or No), a rating scale with five points ranging from "always" 5 to "never" $=1$ (e.g. clinical facilities are selected according to the Positive Practice Environment Criteria). The instrument was developed by a small team of academics from the university nursing schools, and then scrutinized by the project team elected by FUNDISA for content validity by comparing the items with the model content. Adaptations were made until the Project Team was satisfied. It was then pilot tested on three senior academics for clarity and ease of use. It was finally approved and sent out by e-mail to Heads of Schools with a covering letter explaining the objectives of the study and asking for their participation. Two reminders were sent before the data was analyzed. The results were discussed at a FUNDISA business meeting, and a range of completion mistakes were identified. Schools were then given the opportunity to correct such mistakes before the final analysis was done.

\section{Ethical clearance}

Since this was a survey amongst members, ethical clearance was obtained from the Research Portfolio Committee of the organization (FUNDISA).

\section{Results}

\section{Student numbers}

The number of pre-registration B-degree students varied between a small school with only 58 students to a large school with 1073 students (see Table 1). The DUT only launched their B Technology degree in Nursing in 2011, so they have only first- and second-year students. WITS has a B Science in Nursing, and the resulting entry requirements including high levels of Mathematics and Science in grade 12, severely limit their ability to recruit students. NMMU offers a five-year B Cur extended programme, which will thus impact on the percentage of student loss using the stated calculation. The extended programme has an additional year to offer a transitional year for students with poorer grade 12 grades than those with direct entry into the four-year programme. 
Table 5.1: Number of students in pre-graduate programmes in $2012(n=11)$

\begin{tabular}{|c|c|c|c|c|c|c|c|c|c|c|c|c|}
\hline & TUT & DUT & UFS & UL & NMMU & NW-P & NW-M & UP & WSU & UWC & WITS & Average \\
\hline $1^{\text {st }}$ year & 34 & 106 & 84 & 70 & $\begin{array}{l}\frac{110^{* *}}{51: \text { B Cur }} \\
\text { 59: Ext B Cur }\end{array}$ & 71 & 68 & 65 & 80 & 354 & 14 & 96 \\
\hline $2^{\text {nd }}$ year & 38 & 94 & 51 & 55 & $\begin{array}{l}\text { 121: } \\
\text { 75: B Cur } \\
\text { 46: Ext B Cur }\end{array}$ & 36 & 70 & 45 & 47 & 308 & 20 & 80 \\
\hline $3^{\text {rd }}$ year & 30 & $\mathrm{~N} / \mathrm{A}$ & 34 & 50 & $\begin{array}{l}72 \text { (Both } \\
\text { programmes) }\end{array}$ & 26 & 33 & 34 & 68 & 166 & 14 & 53 \\
\hline $4^{\text {th }}$ year & $19(56 \%)^{*}$ & $\mathrm{~N} / \mathrm{A}$ & $47(56 \%)$ & $35(50 \%)$ & $\begin{array}{l}50 \text { (Both) } \\
(45 \%)\end{array}$ & $19(27 \%)$ & 32 (47\%) & $30(46 \%)$ & $52(65 \%)$ & 245 (69\%) & $10(71 \%)$ & $54(57 \%)$ \\
\hline TOTAL & 121 & 200 & 216 & 140 & 353 & 152 & 203 & 174 & 247 & 1073 & 58 & 287 \\
\hline
\end{tabular}

* \% of first-year numbers in fourth year. The \% of fourth-year students compared with the first-years, gives some indication of student loss during the four years, since intakes generally remain steady.

** Please note that the first-year intake for NMMU includes the intake for the B Cur and the B Cur Extended programme. It is essential to state this as it impacts on the calculation of student loss (as per calculation stated).

\section{Dedicated clinical teachers (preceptors)}

All 11 schools employ clinical preceptors, but two (UL and UP) do not have clinical placement coordinators, and only two have teaching associates (TUT and NWU-P). A total of 117 clinical preceptors are employed in 10 schools and only 60 (51\%) of them have a nursing education qualification.

\section{Table 5.2: Training that clinical preceptors receive $(n=11)$}

\begin{tabular}{|l|l|}
\hline No training & UL and TUT \\
\hline Supporting program was introduced late in 2011 & UP \\
\hline $\begin{array}{l}\text { Clinical skill programmes are presented once a term } \\
\text { Short learning programme in the use of simulation-based education } \\
\text { Short learning programme in mentorship } \\
\text { Workshops related to clinical teaching methods } \\
\text { Workshops related to clinical teaching evaluation (formative and summative, using } \\
\text { the self-developed NMMU clinical assessment instruments) }\end{array}$ & NMMU \\
\hline $\begin{array}{l}\text { Orientation : Curriculum Two workshops: PBL } \\
\text { Compact version of the School's preceptorship training programme (Continuing } \\
\text { Education Programme) (UWC See Chapter 6) }\end{array}$ & UWC \\
\hline Short Learning Programme: Preceptorship UFS (see Chapter 6) & UFS; WSU;NWU-P (1:2) \\
\hline
\end{tabular}


The ratio of students to clinical preceptors varies between the years of study and between schools (see Table 3). The highest ratios seem to be during the first year of study, with an average of 1: 40 and the lowest ratios in the third or fourth years, with an average of 1:20 for the third year and 1:17 for forth year students (see Table 3). This might be related to the structure of most B-degrees, which start students in general, and community health nursing, and then offer midwifery and psychiatric/mental health nursing in the senior year. These two fields of nursing demand more time spent on 1:1 supervision and training, in settings such as doing a delivery or managing a therapeutic group. The change in ratio's might also be explained by the loss of students, so that there are less students in the more senior year groups. According to the model, a ratio of between 1: 15 and 1:20 students is ideal.

Table 5.3: Ratio of clinical preceptors: students at schools $(n=11)$

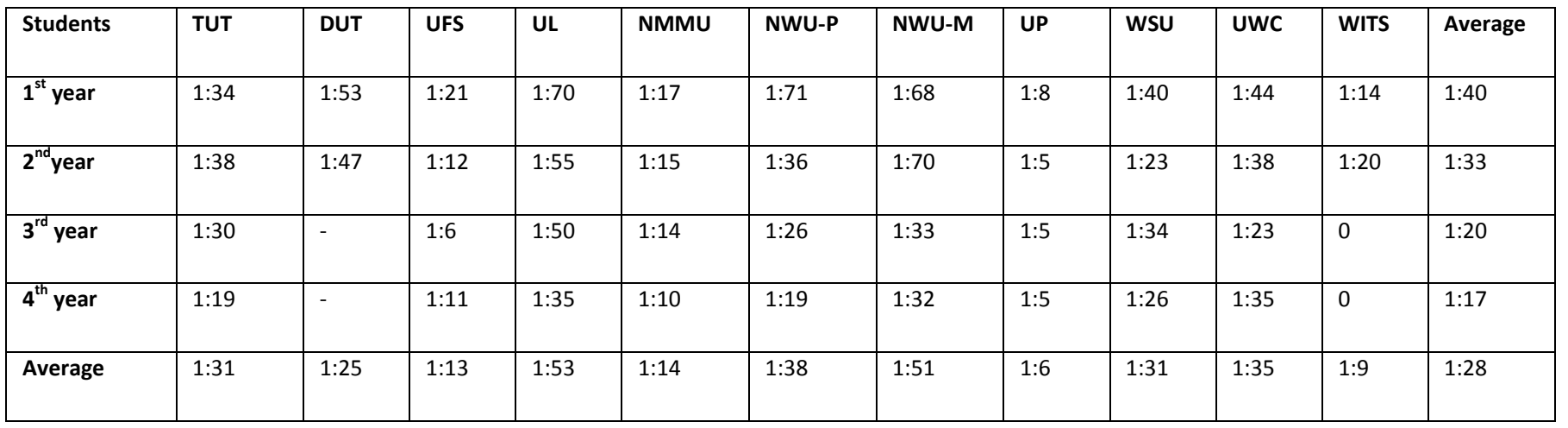

On average, schools report that preceptors spend on average of 1 hour per student per week in clinical practice over the four years, but they generally spend more time with the students during the first two years than in the final two years (Table 4).

Table 5.4: Average number of hours spent per student per week $(n=10)$

\begin{tabular}{|l|l|l|l|l|l|l|l|l|l|l|l|}
\hline Students & TUT & DUT & UFS & NMMU & NWU-P & $\begin{array}{l}\text { NWU- } \\
\mathbf{M}\end{array}$ & UP & WSU & UWC & WITS & Average \\
\hline $\mathbf{1}^{\text {st }}$ year & 2 & 0.5 & 1 & 3 & 0.25 & 0.25 & 1 & 0.5 & 1 & 2 & 1.15 \\
\hline $\mathbf{2}^{\text {nd }}$ year & 2 & 0.75 & 1 & 2 & 0.25 & 0.16 & 1 & 0.5 & 1 & 2 & 1.07 \\
\hline $\mathbf{3}^{\text {rd }}$ year & 2 & N/A & 1 & 2 & 0.25 & 0.5 & 1 & 0.25 & 1 & 2 & 0.95 \\
\hline $\mathbf{4}^{\text {th }}$ year & 0 & N/A & 1 & 2 & 1 & 0.5 & 1 & 0.25 & 1 & 2 & 0.88 \\
\hline Average & 1.5 & 0.6 & 1 & 2.25 & 0.4 & 0.4 & 1 & 0.4 & 1 & 2 & 1.01 \\
\hline
\end{tabular}


In most schools, clinical preceptors communicate with students by means of mobile phones (except WITS), or landline (all except DUT, UL, UP and AWC). None use pagers, and only two schools (UP and NMMU) use social media.

Only one item addressed the utilization of clinical preceptors and this item asked whether the main responsibility of a clinical preceptor is to assess students. Only one university (WSU) indicated that this is the case, while two stated "definitely not" (TUT and UL) and the others ( $n=9)$ indicated that this was sometimes the case.

Another item enquired about the involvement of professional nurses working in health service settings in clinical teaching when preceptors were not available. Four schools indicated that they were definitely involved (DUT, WITS, TUT and UL) and the others $(n=7)$ indicated that they were sometimes involved.

\section{Curriculum elements}

The clinical nursing education and training model has a section indicating how the curriculum should support good clinical teaching. The results of the ratings are summarized in Table 5

Table 5.5: Application of curriculum principles that underpin clinical teaching $(n=11)$

\begin{tabular}{|l|l|l|l|l|l|l|l|l|l|l|l|}
\hline Principles & TUT & DUT & UFS & UL & NMMU & $\begin{array}{l}\text { NWU- } \\
\text { P }\end{array}$ & $\begin{array}{l}\text { NWU- } \\
\text { M }\end{array}$ & UP & WSU & UWC & WITS \\
\hline $\begin{array}{l}\text { Revision of the } \\
\text { curricula every 3-5 } \\
\text { years to address } \\
\text { changes in practice }\end{array}$ & 2 & N/A & 5 & M & 5 & 4 & 3 & 3 & M & 2 & 3 \\
\hline $\begin{array}{l}\text { Focus is on having } \\
\text { enough hours }\end{array}$ & 4 & 5 & 5 & M & 4 & 5 & 4 & 5 & 3 & 4 & 4 \\
\hline $\begin{array}{l}\text { Clinical for learning } \\
\text { and clinical for role } \\
\text { taking are } \\
\text { distinguished }\end{array}$ & 3 & 4 & 5 & 4 & 4 & 4 & 2 & 3 & 4 & 4 & 2 \\
\hline $\begin{array}{l}\text { Placed in clinical to } \\
\text { learn authentic } \\
\text { nursing role }\end{array}$ & 5 & 5 & 5 & 5 & 5 & 5 & 4 & 3 & 3 & 4 & 4 \\
\hline $\begin{array}{l}\text { Students are placed } \\
\text { in a supernumerary } \\
\text { capacity }\end{array}$ & 3 & 1 & 2 & 1 & 2 & 3 & 4 & 2 & 1 & 4 & 5 \\
\hline
\end{tabular}

Key: Always- 5, Often - 4; Sometimes - 3; Seldom - 2; Never - 1. 
The curriculum is revised every $3-5$ years to ensure that the priorities in clinical practice are addressed in the theoretical component in some $(n=3)$ of the schools, although this information was omitted by two schools and two more indicated that this is seldom done.

Even though it has been accepted practice to plan clinical learning placements for students based on the minimum number of clinical hours and procedures as prescribed by SANC, it has become necessary for such planning to be based directly on the curriculum and learning needs of students. The clinical nursing education and training model states that "role functions and competencies should be the focus instead of clinical hours and procedures" (see Chapter 6). In terms of this principle, one would therefore ideally have between a 3 and a 4 rating on this item of the questionnaire. In this survey, five schools had such a rating, but four schools had a rating of 5 , perhaps indicating an over-emphasis on the SANC prescriptions.

The clinical nursing education and training model requires that a distinction is made between clinical practice for learning (experiential learning) and clinical practice for working (work-integrated learning). For instance, one might take students to an antenatal unit to practice taking an obstetric history, without that history being part of the care of the patients and without it becoming part of the patient record. This would be classified as clinical practice for learning. If a student actually worked in such a unit and did the obstetric histories of patients as they came in, this would be clinical practice for working (WIL). Most schools $(n=7)$ indicated that they often or always make this distinction, but some $(n=4)$ acknowledged that it is seldom or never done.

The clinical model requires students to be placed in a clinical setting to learn an authentic nursing role as part of a nursing and / or multi-professional team, and indicates that such placements should constitute $40 \%$ of the total clinical practice time. According to Table 5, this kind of placement is used on a scale between "sometimes" and "always" by most schools $(n=9)$. WITS is the only university that uses this approach exclusively.

The next item enquired about the supernumerary placement of students, which means that students are brought into contact with the healthcare user in order to achieve specific learning outcomes but do not form part of any clinical service team. Six of the 11 universities seldom or never use this approach.

According to the clinical nursing education and training model, the ideal theoretical to practice ratio in this programme should be 30 to $70 \%$. In all universities, the ratio is slanted towards theory (see Table $6)$. 
Table 5.6: The theory to practice ratio in the curriculum $(n=10)$

\begin{tabular}{|l|l|l|}
\hline $\mathbf{5 0 \% - 5 0 \%}$ & $\mathbf{6 0 \% - 4 0 \%}$ & $\mathbf{8 0 \% - 2 0 \%}$ \\
\hline NWU-P & UP & UWC \\
\hline WSU & WITS & \\
\hline UL Limpopo & UFS & \\
\hline & TUT & \\
\hline & NWU-M & \\
\hline & NMMU & \\
\hline
\end{tabular}

\section{Nursing academics}

The clinical model ascribes particular functions to the nursing academics in terms of the clinical component of their students' programme. The results of this part of the questionnaire are summarized in Table 7.

According to the clinical nursing education and training model, academic staff should have a preceptor role and are responsible for specific group(s) of students. This is at least partially applied in all schools. They should also run group supervision sessions for clinical preceptors involved with their students. This is done consistently in only four schools.

Table 5.7: The involvement of nursing academics in the clinical component $(n=11)$

\begin{tabular}{|l|l|l|l|l|l|l|l|l|l|l|l|}
\hline & TUT & DUT & UFS & UL & NMMU & NWU-P & NWU-M & UP & WSU & UWC & WITS \\
\hline Involved & 2 & 3 & 3 & 3 & 3 & 3 & 2 & 2 & 2 & 3 & 3 \\
\hline Supervision & 1 & 3 & 3 & 1 & 3 & 3 & 2 & 1 & 1 & 2 & 2 \\
\hline Honorary & 1 & 2 & 1 & 1 & 1 & 2 & 1 & 1 & 1 & 1 & 3 \\
\hline Accountable & 1 & 3 & 2 & 3 & 3 & 3 & 3 & 2 & 2 & 3 & 3 \\
\hline Competent & 3 & 3 & 3 & 3 & 3 & 3 & 3 & 2 & 3 & 3 & 2 \\
\hline Practice & 1 & 1 & 1 & 1 & 1 & 1 & 1 & 1 & 1 & 1 & 1 \\
\hline Sabbatical & 1 & 1 & 1 & 1 & 1 & 1 & 1 & 1 & 1 & 1 & 1 \\
\hline
\end{tabular}

Key: Yes - 3, Partially - 2, No - 1

To regulate the relationship between academics and clinical services, the clinical nursing education and training model suggests that academic staff should hold honorary appointments in clinical facilities where students are placed. This was found to be the case in only two universities. 
Academic staff is supposed to be ultimately responsible for quality assurance of the clinical learning experience of students, even though much of this will be done by clinical preceptors. This was the case in only three schools.

Academic staff are expected to remain clinically competent in their field of specialization and, to do this, they are expected to do some clinical practice (work, not clinical supervision) every year, and to spend some of their sabbatical time in the clinical field. While almost all schools ( 9 out of 11) indicated that they expected clinical competence, none of them required clinical practice or the use of sabbatical leave for improving clinical competence.

Process of clinical experience

The process and practices around clinical experience of students are summarized in Table 8. Simulation is part of the preparation of students for clinical practice in most $(n=10)$ schools and, similarly, every clinical preceptor's visit is usually documented.

Much less consistently done are pre-clinical discussions (where the clinical preceptor is present) as part of the preparation of students for placement in a specific clinical area, while post-clinical discussions (debriefing) with students occurs only sometimes or rarely. Clinical preceptors are very seldom available over weekends.

\section{Table 5.8: The process of clinical placement $(n=11)$}

\begin{tabular}{|l|l|l|l|l|l|l|l|l|l|l|l|}
\hline & TUT & DUT & UFS & UL & NMMU & NWU-P & NWU-M & UP & WSU & UWC & WITS \\
\hline Simulation & 4 & 5 & 5 & 4 & 5 & 4 & 5 & 4 & 4 & 5 & 3 \\
\hline Document & 5 & 5 & 4 & 5 & 4 & 4 & 5 & 4 & 3 & 4 & 4 \\
\hline Pre-clinical & 5 & 5 & 3 & 3 & 4 & 4 & 2 & 1 & 2 & 4 & 2 \\
\hline Post-clinical & 5 & 5 & 2 & 4 & 5 & 3 & 3 & 2 & 3 & 3 & 2 \\
\hline Weekends & 1 & 3 & 1 & 4 & 1 & 4 & 1 & 1 & 1 & 1 & 1 \\
\hline
\end{tabular}

Key: Always - 5; Often - 4; Sometimes - 3; Seldom - 2; Never - 1.

\section{Clinical Placements}

Responses regarding the management of clinical placement of students for work-integrated learning are summarized in Table 9. A set of guidelines in this regard is part of the clinical nursing education and training model. 
Table 5.9: The management of clinical placements of students $(n=11)$

\begin{tabular}{|l|l|l|l|l|l|l|l|l|l|l|l|}
\hline & TUT & DUT & UFS & UL & NMMU & NWU-P & NWU-M & UP & WSU & UWC & WITS \\
\hline $\begin{array}{l}\text { Regional co- } \\
\text { ordination }\end{array}$ & 5 & 1 & 4 & 1 & 4 & 1 & 1 & 2 & 5 & 4 & 1 \\
\hline $\begin{array}{l}\text { Electronically } \\
\text { available }\end{array}$ & 5 & 5 & 5 & 2 & 5 & 5 & 3 & 1 & 1 & 4 & 4 \\
\hline $\begin{array}{l}\text { Minimum of 1 } \\
\text { month }\end{array}$ & 3 & 3 & 4 & 4 & 4 & 3 & 2 & 4 & 2 & 5 & 2 \\
\hline $\begin{array}{l}\text { Numbers } \\
\text { taken into } \\
\text { consideration }\end{array}$ & 5 & 5 & 4 & 5 & 5 & 5 & 3 & 2 & 3 & 5 & 3 \\
\hline $\begin{array}{l}\text { Equitable } \\
\text { access to } \\
\text { public health } \\
\text { services }\end{array}$ & 4 & 3 & 3 & 5 & 5 & 4 & 4 & 4 & 4 & 4 & 4 \\
\hline $\begin{array}{l}\text { Placed } \\
\text { according to } \\
\text { clinical } \\
\text { outcomes }\end{array}$ & 5 & 5 & 5 & 4 & 5 & 5 & 4 & 3 & 4 & 5 & 4 \\
\hline $\begin{array}{l}\text { PPE taken into } \\
\text { account }\end{array}$ & 4 & 4 & 3 & 4 & 3 & 2 & 4 & 4 & 3 & 3 & 5 \\
\hline Average & 4.4 & 3.7 & 4 & 3.6 & 4.4 & 3.9 & 2.9 & 2.9 & 3.1 & 4.3 & 3.3 \\
\hline
\end{tabular}

Key: Always - 5; Often - 4; Sometimes - 3; Seldom - 2; Never - 1.

The co-ordination of clinical placement of undergraduate students is done on a provincial / regional basis in only three provinces, but this must be interpreted with caution, since TUT says that this is always done, while other universities in the same province (WITS) or region (UP) says it is never or seldom done. The placement plan of students is always electronically available $(n=5)$ or most of the time $(n=2)$ in most schools, but never or seldom in three.

In order to allow students to become comfortable in a clinical area and still have enough time to learn the competencies they should in that area, the clinical nursing education and training model suggests that they are placed in a specific clinical area for a minimum period of at least one month at a time. Only two universities indicated that this was always the case, while six schools respectively indicated that it is only sometimes (3) or rarely (3) done. This means that most students are places in a specific clinical area for less than a month.

The number of students already allocated to a specific clinical area should be taken into consideration when considering the placement of more or other students, and this is the case in most $(n=7)$ settings. The universities also indicated that most of them often $(n=7)$ or always $(n=1)$ have equitable access to public health services for the clinical placement of undergraduate students. The clinical outcomes of 
students are generally always $(n=6)$ taken into consideration for the clinical placement of undergraduate students and clinical facilities are usually or always $(n=6)$ selected according to the Positive Practice Environment Criteria (PPEs).

Implementation

In order to identify the problems experienced by universities in implementing the clinical nursing education and training model, they were asked a qualitative question about this aspect and how they addressed these problems. The results are reflected in Table 10.

Table 5.10 Problems with implementation of the model and possible solutions $(n=11)$

\begin{tabular}{|c|c|}
\hline Problem & Solution \\
\hline $\begin{array}{l}\text { 1. Students are not given the opportunity to apply what } \\
\text { they have learned, due to lack of adequate PPEs. }\end{array}$ & 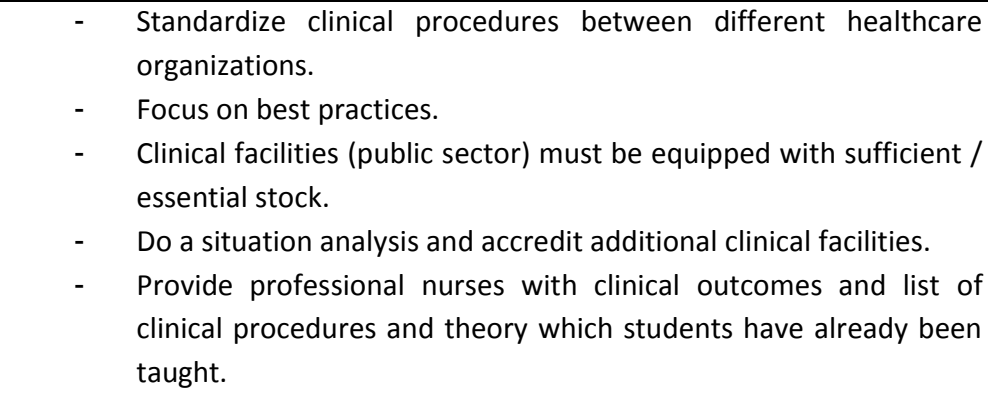 \\
\hline 2. Recruitment of clinical preceptors. & $\begin{array}{l}\text { - Collaborate with healthcare institutions to identify and appoint } \\
\text { appropriate clinical preceptors. } \\
\text { - Flexible conditions of service with regard to weekends and night } \\
\text { duty should attract them. } \\
\text { - Short learning programs for clinical preceptorship should be } \\
\text { developed and offered. }\end{array}$ \\
\hline $\begin{array}{l}\text { 3. Availability of professional nurses to supervise and } \\
\text { educate students in the practice environments } \\
\text { - High workload } \\
\text { - } \quad \text { Not part of their job description } \\
\text { - Do not understand the process } \\
\text { - Lack of knowledge and skills }\end{array}$ & 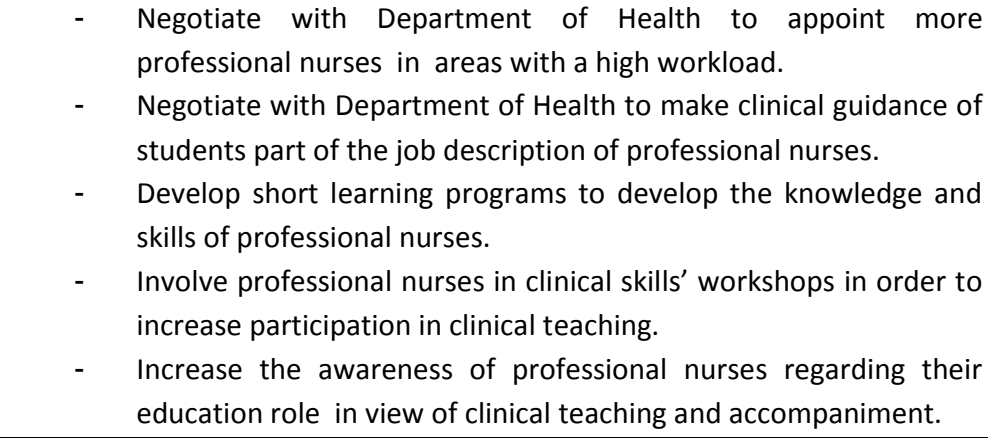 \\
\hline $\begin{array}{l}\text { 4. Lack of time to update clinical skills and competence of } \\
\text { academic staff. }\end{array}$ & $\begin{array}{l}\text { - Create and formalize time periods, for instance in the academic } \\
\text { recess, to allow academics to engage and / or work in clinical } \\
\text { healthcare institutions } \\
\text { - Deliberate process to reduce academic workloads of individuals to } \\
\text { accommodate the clinical practice hours of academics }\end{array}$ \\
\hline $\begin{array}{l}\text { 5. Traditional and outdated practices performed by } \\
\text { professional nurses responsible for students in the clinical } \\
\text { settings. }\end{array}$ & $\begin{array}{l}\text { - Organize clinical skill workshops integrating the best practices into } \\
\text { clinical teaching. } \\
\text { - Identify best practice champions in clinical healthcare institutions } \\
\text { and encourage active participation and involvement in order to } \\
\text { enhance best practice integration. }\end{array}$ \\
\hline
\end{tabular}




\section{Discussion}

Although a $100 \%$ response would have been ideal in terms of a baseline survey, the 11 schools who responded represent all seven provinces with university nursing schools, and both the oldest (UP) and the youngest (DUT) schools offering this kind of programme. It also includes the smallest (WITS) and the largest (UWC) and, as such, can be seen as a fair representation of the university nursing sector offering pre-registration nursing programmes.

Only two schools have significantly lower first-year intakes than the other schools. In the case of TUT, they have applied to increase their numbers, based on the creation of additional clinical learning opportunities at their mobile clinic. This clinic, in the informal settlement of Soshanguve, was funded by Atlantic Philanthropies and will allow them to take in 50 additional students per year. WITS has a very different problem with regard to increasing their intake, but it would be beneficial if this prestigious university could increase their annual intake.

The calculation of student attrition rates is a cross-sectional comparison instead of the more accurate time-series design, and the attrition rate also does not follow the students towards completion, but only to their fourth year. The attrition rate at universities in Sub-Saharan Africa is generally 50\% (Higher Education in S-S Africa, 2009) and, according to the Human Sciences Research Council, the rate specifically in South Africa is 50\%, with $30 \%$ dropping out in the first year (Letseka \& Maile, 2008). If the drop-out rate for university nursing programmes is indeed $43 \%$, it is lower than the national average, and indicates that these demanding programmes do not lead to greater loss than any average programme. However, losing $43 \%$ of young people who indicated an interest in the profession is still too high.

The clinical nursing education and training model does not stipulate that clinical preceptors should be registered nurse educators, but does require them to have special training in clinical teaching and learning. It appears that only four universities have provided targeted formalized training for preceptors. With regard to the ratio between clinical preceptors and students, the ratios are generally slightly less favourable than that suggested by the model. However, one wonders whether the rather absent clinical preceptors in the first and second years could contribute to the loss of students. While the senior student seems to be receiving an acceptable level of clinical support, this seems not to be happening in the first and second year.

In terms of curriculum elements, almost every university has issues which can be improved. Generally, however, it seems that the ratio between clinical teaching and learning and theoretical teaching and learning needs some attention. The number of credits in a four-year professional programme is usually about 480 credits (or 120 credits per annum) and reflects 4800 notional hours of student learning. If one accepts about 3500 hours as the usual number of hours for clinical practice, the clinical teaching model suggests that role-taking practice (WIL) should comprise $40 \%$ of the total clinical practice, or 1400 hours. In most schools it is probably significantly higher. However, schools will have to become more accustomed to calculating such proportions, and ensure that their programme falls within the curriculum guidelines. 
The finding that there is no structured way in which nurse academics are required to keep themselves clinically competent indicates a significant gap in the planning and policies of university nursing schools. It is not good enough to expect clinical competence, without creating the structure for academics to maintain their own expertise.

Most schools use simulation in preparing students for WIL, but there seems to be much variation. It appears that other methods of student support, such as pre-and post-conferences is being used on a very limited basis It is disconcerting that support for students in clinical practice through clinical preceptors is very limited over weekends, when one can expect the service staff to be at a minimum as well. It would be interesting to explore the experience of students over weekends further, and also to link it with student loss.

There seems to be no pattern in the management of clinical placements, with some universities doing much better than others, sometimes in the same province. It is probably an area in which each university has to address its own problems.

Of the five problems schools are experiencing with implementation of the clinical nursing education and training model, three are related to the practice environments. In this clinical model, it is recommended that nursing schools be responsible for evaluating whether a clinical setting is a Positive Practice Environment, and that students only be placed in such settings. Although it was recognized that this might limit placement settings, it was considered that the Clinical Training Grants and incentives such as appointing good role models as clinical associates, might be used to incentivize clinical units to aspire to become classified as PPEs.

Limitations of the study

The section about clinical placement highlighted the problem that schools are still unfamiliar with the nomenclature of the clinical nursing education and training model and may interpret questions differently. This was also the case with the item that addressed the number of clinical preceptors per year group, in which some schools gave such impossible figures that the data had to be reviewed in consultation with the schools. If data was not so obviously wrong, incorrect data might still have been included. The possibility that invalid data was provided is a limitation of the study which should improve as the model becomes more familiar to nurse educators.

\section{Conclusion}

It is recommended that individual nursing schools address the problems highlighted by this survey in their own practice. It is also recommended that schools that did not participate complete the questionnaire and compare their practice with that of their peers in this study. We remain keen to receive such completed questionnaires to add to our baseline data.

It is further recommended that nursing schools hold workshops and presentations on the clinical nursing education and training model in order for their own staff to become familiar with the components and nomenclature of the model. FUNDISA supports this model and advocates for its use and for the consistent use the nomenclature in order to promote understanding across schools and 
provinces. We cannot do this without becoming more familiar with the model than we seem to be at the moment.

Lastly, it is recommended that researchers be encouraged to research targeted aspects of the clinical nursing education and training model, such as the impact of limited preceptors during the first year of study, or the impact of pre- and post- clinical conferences on student learning and experience.

Clinical training and education lie at the heart of nursing education. The clinical nursing education and training teaching model is aimed at addressing specific limitations in the current nursing practice of South Africa, and the survey described above makes explicit some of the limitations in the practice of nursing schools at universities in this regard. It is with great expectations that one looks forward to seeing a change in this picture over time.

\section{References}

American Nurses Association (2011): Funding Recommendations By Title VIII Nursing Workforce Development and Managed Health Clinics. [online] http//www.nursingworld.org/Title VIII.pdf

Council of Higher Education (2011) Work-Integrated Learning: Good Practice Guide. HE Monitor No.12. Pretoria: CHE.

Higher Education in Sub-Saharan Africa (no date) Statistics on Higher Education in SS Africa. http://ent.arp.harvard.edu/Africanhigher education. Accessed $7^{\text {th }}$ May 2012.

Letseka, M. and Maile, S. 2008. Higher university drop-out rates: a threat to South Africa's future. Pretoria: Human Sciences Research Council Press Release.

Mekwa, J. 2001. Transformation in nursing education. South African Health Review 2000: 271-284. Durban: Health Systems Trust.

Nursing and Midwifery Council 2004b. Standards of proficiency for pre-registration nursing education. London: NMC. Available from http://www.nmc-uk.org/

Nursing and Midwifery Council 2004c.Standards of proficiency for pre-registration midwifery education. London: NMC. Available from www.nmc-uk.org/ 